\title{
翻转课堂教学模式对大学生英语自主学习能力的影响一一 喀什大学英语教学为例
}

\author{
马依努尔・阿布都吾甫尔 \\ 喀什大学外国语学院 \\ DOI:10.32629/er.v2i8.1989
}

\begin{abstract}
[摘 要] 随着信息技术的发展,翻转课堂教学模式逐渐成为当今教育界教学新方法的引领者。翻转课堂教学模式改变了传统 课堂教学的流程, 在教育界掀起了巨大的波浪。在这一教学模式的影响下,教育界可谓是发生了翻天覆地的变化, 尤其是对大学 生英语教学来说。本文通过翻转课堂教学模式在喀什大学的实施, 来探索这一教学模式对大学生英语自主学习能力的影响,期 望对大学生英语教学有一定的借鉴意义。
\end{abstract}

[关键词] 翻转课堂; 喀什大学; 英语教学; 英语自主学习能力

\section{引言}

经过研读近几年的文献, 并经过梳理, 发现有关翻转课 堂的研究成果颇多, 而且涉及到了语数英各学科的教学。但 是基于实践的基础上, 专门针对大学生英语自主学习能力的 影响的研究是有限的, 并没有涉及的太多, 这也为本文的研 究打开了突破口。基于此, 本文在实践的基础上, 以喀什大学 英语教学为例, 研究翻转课堂教学模式的实施对大学生英语 自主学习能力的影响, 期望对以后的教育实践的改革具有一 定的实践意义。

\section{1 理论的概述}

翻转课堂是在互联网技术的带动下, 而在美国率先兴起 的新型教学模式。详细地来讲, 是对课堂内外的时间进行规 划调整, 变更传统的学习决定权, 将学习的决定权从教师转 移给学生的一种混合式的教学模式。这一教学模式主要分为 四个环节: 首先是课前教学资源的开发, 接着是课前的自主 学习, 然后是课上的师与生的互动, 以及最后的学习评价。从 概念中可得出, 学生在获得知识的过程中, 教师是其引导者、 帮助者以及合作者, 而一课堂中的真正的主人是学生。

\section{2 对喀什大学的大学生英语自主学习能力的影响}

2.1 对英语学习动机的影响

根据翻转课堂实施的环节可知, 学生在课堂中充分发挥 了主体作用, 更多的是自主性的学习。课前的预习, 课上的互 动, 激发了学生学习的主动性以及趣味性、积极性。对英语 产生了兴趣, 有了学习的自觉性, 那么学习的动机就会明显 的加强, 不再是被动地学习英语, 而是把学习当成乐趣。长时 间地自主性学习, 会使其加强对学习的认识, 明白学什么, 怎 么学, 为什么而学, 为了谁而学, 学习的最大受益者是谁。这 样学习的动机在逐渐地加强, 学习的目的性就自然而然地随 之加强。从近三年的喀什大学的英语课堂中大学生的学习成 绩以及课堂表现可以看出, 在未实施翻转课堂教学模式前, 按照传统的教学模式, 学生普遍的预习效果不是很好, 都是 在课堂中现教现学, “填鸭式” 的学习, 喂什么, 吃什么, 主动
学习的能力不强, 全班的成绩浮动性较强, 不稳定, 优劣差异 明显。而在实施翻转课堂教学模式之后, 通过微信, $Q Q$ 等网络 途径, 把要学习的内容传到班级群里面, 发现下载率、点击率 都是接近百分之百的, 而且教师上课提问有关英语教学内容 的时候, 学生基本上能够回答出来。可见, 学生学习的主动性 有了, 能够主动参与到学习中。另外, 在课堂讨论的过程中以 及课下的闲聊中, 能够发现学生们会谈及许多课本上没有的 知识。学生有了学习英语的兴趣, 有了学习的目标, 班级的英 语过级率相比原先未实施翻转课堂之前明显提高了很多。这 都是翻转课堂模式实施, 让喀什大学的学生有了自主学习英 语的动机。

\section{2 对英语学习时间的影响}

翻转课堂教学模式在喀什大学英语教学中的应用, 对于 教师和学生来说, 都节省了大量的时间, 在课堂上充分利用 有限的 45 分钟, 提高了课堂上学生学习的效率, 也相应地提 高了教学质量, 顺利地完成了课程所规定的教学任务以及教 学目标, 符合新时代英语课程教学对大学生的要求, 这正是 高速度、经济化社会发展的产物。因为翻转课堂教学模式的 实施, 学生在课下预习的效果相对于传统的教学模式来说, 有了显著性的提高。线上的多媒体的课前预习, 让学生对要 所进行的新课程有了初步的了解, 圈住自己的疑难点, 以便 课上进行。预习效果的极佳, 学生懒散度消退, 这样为教师在 课堂上的讲解节省了大量的时间, 学生也很少出现不知教师 所云的情况, 能够轻易地抓住课堂上的重难点。这样学生就 不再为学习英语发愁, 那么学习英语so easy, 有了学习兴趣, 学习效率就相应提高。虽然课下的线上或者线下的英语自主 预习会占用学生课下的一部分时间, 但这对于大学生来说, 是一种自我的挑战, 能够更好地约束自己, 合理规划自己现 有的时间, 具有时间意识, 而不是整天的无所事事, 沉迷于网 络游戏, 只会安逸享乐, 而是明白自己作为大学生所具有的 责任意识, 如何更好地实现自己的人生价值, 更好地做社会 的接班人和建设者。需要说明的是, 目前, 喀什大学英语教学 
多集中采用的是线上的自主预习。相较于原来的传统教学, 学生的预习效果有了很大的进步, 主要体现在以下两方面: 课前提问学生回答得特别积极, 哑口无言的情况减少了; 课 前单词的默写的准确率也提高了, 据统计结果高达 $70 \%$, 这减 少了课堂记单词时间, 为教师誊出空余时间进行单词以及其 他部分讲解, 大大地提高了课堂效率。可见, 翻转课堂教学模 式的应用, 能够让大学生调整好自己的学习计划, 合理规划自 己的时间, 能够达到良好的学习效果, 满足自身发展的要求。

\section{3对英语学习方法的影响}

对于英语这种非本土化的语言的学习, 需要讲究方法、 效率。教师不注重教学方法的应用, 不仅容易使学生丧失学 习的兴趣, 还容易造成事倍功半的结果。翻转课堂教学模式 在英语教学中的应用就很好地扭转了大多数学生不愿意学 习英语的不良局面。翻转课堂教学模式在互联网的带动下, 多媒体的运用, 使学生对事物产生了新鲜感, 学习的劲头就 会提升, 英语课上就会集中注意力。在喀什大学的英语课堂 上, 很少出现课上 “扑倒一片” 的现象, $85 \%$ 以上的学生都是 在聚精会神地听讲师讲课。(据调查, 排除因生病睡觉的学生, 实际上上课听讲的人数所占的比例是 $95 \%)$ 。

不仅如此, 相对于传统的教学方法来说, 翻转课堂教学 模式的运用, 优化了学生的学习方法。学生在无形当中, 具有 了自我规范的学习方法。学生依靠着多媒体的教学, 课前能 够认真地预习, 圈出自己不会的地方; 课上带着疑问认真听 讲, 解决自己的疑难点; 考前能够很好地复习, 归类、总结自 己的学习内容。学生一旦适应这一连套的环节, 就会改变自 己不好的学习习惯, 塑造出属于自己的学习方法。因为翻转课 堂是在多媒体等信息技术的运用下实施的, 所以多媒体的运 用, 相对于枯燥、乏味的传统教学法来说, 不仅生动、有趣, 而 且集图片、声音、动画等为一体的视频的形象化的展示, 促进 了学生的理解, 加深了学生的记忆。其次, 因为学生课前对新 知识, 通过视频的学习, 做到了很好的课前预习, 所以, 在课上 的学习就会有选择性的进行, 很好地运用了复述法。学生会重 点解决自己的疑问, 自己会的地方在课上会过滤性的复述, 这样学生完全掌握的同时, 强化了记忆, 还会有新的认识。从 喀什大学的学生在英语课堂上的学习效果来看, 学生的课上 反应是快速的、灵敏的。据课下的调查报告显示, 翻转课堂 教学模式的进行, 学生强化了复述法, 有效地利用了课上的 学习时间。再者, 翻转课堂在大学生英语学习中的运用, 强化
了大学生对联想法、归类法的使用。英语这种语言学习, 不 是就题论题, 单词、词汇、语法的学习需要举一反三, 融会贯 通。课前预习的铺垫, 大学生在课上教师的指引下, 由这一个 单词联想到与其有关的单词, 就会不自觉地发现英语这门语 言的规律, 把相近、相同的词汇进行归类。掌握了联想法和 归类法, 那么对于英语语法的学习就不是问题。根据喀什大 学学生反应, 英语的学习对于他们来说不是什么难事。这几 年英语的挂科率几乎是零就是最好的证明。对于向社会的大 门走得更近的大学生来说, 团结协作的精神是其必胜的法宝, 而翻转课堂教学模式的实施, 也在无形当中培养了大学生们 极需的这种精神。英语课堂中, 学生们需要扮演角色, 朗读句 子来掌握语法、句型。翻转课堂教学模式下, 学生们之间多 以小组等合作的方式来讨论问题, 并展开英语课堂中的各种 活动。学生们在互帮互助的过程中, 提升了解决问题的能力, 并获得了成就感、自豪感。翻转课堂教学模式在喀什大学英 语课堂上的实施, 可谓是一举多得。

\section{3 结语}

本文通过翻转课堂教学模式在喀什大学英语教学中的 运用, 发现翻转课堂教学模式对大学生英语自主学习能力具 有促进作用, 提高了学生的英语自主学习能力。在英语学习 动机方面, 课前预习, 培养了学生自主学习的能力, 有目的性 地去学习英语。在英语学习时间方面, 大学生能够合理地分 配自己的时间, 从而满足自身的发展。在英语学习方法方面, 优化大学生的学习方法, 充分掌握联想法、归类法、复述法 的综合运用, 无形中规范学习习惯, 养成良好的学习作风, 培 养团结协作的精神。所以, 要加大翻转课堂在全国各学科课 堂中的运用。

\section{[参考文献]}

[1]肖雨欣.翻转课堂教学模式对高中生英语自主学习 能力影响的研究[D].哈尔滨师范大学,2019,(07):65.

[2]张悦, 赵秀䎦.翻转课堂教学模式对英语专业学生自 主学习能力的影响研究 [J]. 语言教育,2017,5(04):26-32.

[3]容铭蔚.翻转课堂教学模式下高中生英语自主学习能 力效果研究[D].四川师范大学,2018,(12):83.

\section{作者简介：}

马依努尔・阿布都吾甫尔(1968--), 女, 新疆喀什人, 维吾 尔族, 喀什大学外国语学院教师, 副教授, 研究方向: 英汉双语 对比。 